\title{
The influence of attitudes on Transit-Oriented Development: an explorative analysis
}

\section{Abstract}

Transit-Oriented Development (TOD), where compact, mixed-use neighbourhoods are being realized around existing or new public transit stops, is a promising tool to restrict urban sprawl and stimulate sustainable travel modes. However, TOD's are not always as easy to implement at every location. In high-density city centres a TOD is relatively easy to implement, since density and diversity are already high and most residents have a positive stance toward car alternatives due to self-selection processes. In more low-density suburbs, however, the situation is more difficult. There is not only the problem of adapting the built environment, but also the problem that most initial residents have a preference for car use, since they chose their neighbourhood based on the physical characteristics of the initial neighbourhood. In this viewpoint we will look at how travel-related attitudes and residential self-selection can affect the success rate of TOD's in three different situations. It seems that taking into account attitudes is especially important for the realisation of TOD's in lowdensity neighbourhoods.

\section{Introduction}

Previous research has shown that walking, bicycling and public transportation use in lowdensity neighbourhoods is significantly lower than in compact, mixed-use neighbourhoods, while car use is significantly higher (e.g., Cao et al., 2009; Cervero, 1996; Ewing \& Cervero, 2010; Mokhtarian \& Cao, 2008). This can be partly explained by the built environment of these neighbourhoods. Low-density neighbourhoods (mostly suburbs) have higher average 
distances, discouraging walking and cycling. Besides, these car-oriented neighbourhoods have limited public transportation services resulting in low frequencies and long average distances to public transportation stops. Urban planners have therefore, from the 1990 's onwards, tried to reduce car use (and the accompanying air pollution and congestion) by adapting the built environment. Concepts such as New Urbanism (in the USA), Compact City (in Europe) and Transit-Oriented Development (in the USA and later in Europe and Asia) aim to reduce car use and travel distances by creating neighbourhoods with a high density, a high diversity and a design oriented toward public transportation and non-motorized travel (Cervero, 1996; Schwanen and Mokhtarian, 2005). However, more recent research has shown that also travel-related attitudes affect travel mode choice; a positive stance toward a certain mode of transportation will result in a higher use of that mode. However, these attitudes can also affect other, non-travel related aspects, such as the residential location choice. Individuals with an affinity toward a certain kind of travel often choose a residential location that enables them to travel as much as possible with their preferred travel mode (residential self-selection) $^{1}$ (e.g., Bhat $\&$ Guo, 2007; Cao et al., 2007; Handy et al., 2005, van Wee, 2009). Since most low-density suburbs were designed to be well accessible by car, car loving persons will try to self-select themselves in these neighbourhoods. Efforts to reduce car use in these neighbourhoods should therefore not only focus on changing the built environment, but also on changing travel-related attitudes. Most studies even state that attitudes have a bigger effect on travel behaviour than the built environment and that residential self-selection attenuates the effects of the built environment on travel (Guo and Chen, 2007; Mokhtarian and Cao, 2008). It has to be noted, however, that such a travel-

\footnotetext{
${ }^{1}$ Residential self-selection could also result from socio-demographic traits (e.g., low-income and zero vehicle household choosing to live in an urban neighborhood in order to use public transportation). However, in this study, just as in most travel behaviour studies, we only focus on attitude-induced self-selection (Mokhtarian \& Cao, 2008; Schwanen \& Mokhtarian, 2005).
} 
related residential self-selection process is not always the case. Certain elements, such as income, distance to work or varying preferences within households, can constrain the residential location choice and might thus result in a dissonance between the actual neighbourhood and the neigbourhood type enabling residents to realize their preferred travel behaviour (Schwanen \& Mokhtarian, 2004, 2005; De Vos et al., 2012). Such a residential dissonance can have an impact on travel behaviour since the preferred transportation modes of dissonant residents are not ideally available in their residential neighbourhood. $^{2}$

\section{Transit-Oriented Development}

The TOD concept, first proposed by the American architect Calthorpe (1993) and later on gaining attention in Europe and Asia, developing compact, mixed-use neighbourhoods around existing or new public transit stops offering frequent and high-quality public transportation, is an interesting tool to reduce car use (Cervero, 1998, 2004; Curtis et al., 2009; Dittmar et al., 2004; Loo et al., 2010; Mu \& de Jong, 2012). The compact development around public transportation stops can increase ridership since a considerable amount of residents live in close proximity of these stops. Furthermore, the high density and diversity decreasing average travel distances - and the design oriented toward non-motorized travel stimulates active travel (Curtis \& Olaru, 2010). TOD's distinguish themselves from Transit Adjacent Developments (TAD's), whereby public transportation stops are surrounded by low-density, single-use and car-friendly developments (Dittmar et al., 2004; Renne, 2009). These TAD's might therefore not lead to a decrease in car use. Besides (positively) affecting

\footnotetext{
2 In the remainder of this paper we refer to residential dissonance as a dissonance between the actual neighbourhood and the neighbourhood type enabling residents to realize their preferred travel behaviour.
} 
travel behaviour of people, TOD can also be regarded as a spatial planning tool; the realization of compact, mixed-use neighbourhoods can help to reduce urban sprawl (which in turn also reduces car use) (e.g., Cervero, 2004; De Vos \& Witlox, 2013; Olaru et al., 2011).

Although studies analysing differences in implementing TOD's in high-density versus lowdensity neighbourhoods/cities are limited, it seems that the implementation of TOD's in high-density environments (e.g., Curitiba, Hong-Kong, Seoul) is more effective than in their low-density counterparts (e.g., Perth) (Cervero \& Kang, 2011; Curtis, 2008; Loo, 2009; Sung \& Oh, 2011). There are numerous aspects that can help explain this. First of all, it is not easy to adapt a low-density, car-oriented neighbourhood into a dense, mixed-use neighbourhood. Besides, in some cases, the importance to adapt the environment into a compact neighbourhood is not recognized, resulting in transportation stops as islands in low-density car-based environments (Curtis, 2008). An aspect left out of account in studies on TOD is the effect of travel-related attitudes on travel mode choice. Since car-loving persons tend to selfselect themselves in low-density suburbs (residential self-selection), most suburbanites might not be interested in travelling by public transportation, even if it is highly accessible after adapting the built environment. This can have negative effects on public transportation ridership and the overall success rate of TOD's.

\section{TOD typologies}

In order to show how attitudes and residential self-selection can affect the success rate of TOD's we have made a subdivision of three types of TOD's, based on the initial stage of development. Although classification methods of TOD's already exist, most of them subdivide TOD's based on an evaluation of existing TOD's, such as walkability (Schlossberg \& 
Brown, 2004), vehicle miles travelled (CTOD, 2010) and the connectivity of the public transportation node (Bertolini, 1999; Zemp et al., 2011). Cervero (1998) distinguishes four types of TOD's based on the evolution of cities toward transportation oriented cities (with numerous TOD's). Recently, Kamruzzaman et al. (2014) and Singh et al. (2014) have made a classification of TOD's based on whether neighbourhoods have the potential to develop as a TOD (using, among others, density and diversity indicators). Although these are interesting classifications, we prefer a new subdivision, based on the initial stage of development: New TOD's; High-density TOD's and Low-density TOD's (Figure 1).

- (i) New TOD's: The development of new neighbourhoods around new public transportation services. This type is comparable to Cervero's (1998) adaptive cities. Compact and mixed-use neighbourhoods are developed around stations of new public transportation services.

Famous examples can be found in Copenhagen (Denmark), Stockholm (Sweden) and Curitiba (Brasil) (Knowles, 2012; Smith \& Raemaekers, 1998; Stojanovski et al., 2012). These cities tried (and mainly succeeded into) guiding urban development along linear corridors with high quality public transportation (i.e., public transportation with high frequency and high capacity). This has resulted in a 'pearl on a necklace' development, whereby mixed-use developments are concentrated around public transportation stops (Cervero, 2007).

- (ii) High-density TOD's: New public transportation services in compact, mixed-use areas. High-quality public transportation is provided in and between existing neighbourhoods with a high density and diversity. This type is comparable with Cervero's (1998) strong-core cities. 
European and especially Asian cities have a higher density than North-American or Australian cities. However, even European and Asian cities have to deal with high car use (Newman and Kenworthy, 1996). In order to make car alternatives more appealing, some cities (e.g., Zurich (Switzerland) and Seoul (Korea)) have introduced high-quality public transportation, together with mixed-use development and a design to discourage car use (Cervero \& Kang, 2011; Newman \& Kenworthy, 1996; Sung \& Oh, 2011). TOD planning in high-density cities does not need to emphasize on density itself but mainly on other TOD factors, such as diversity and design.

- (iii) Low-density TOD's: Increasing density and diversity of suburban-style neighbourhoods around new public transportation services. This type is a combination of offering improved public transportation services and increasing the density and diversity of low-density developments.

A lot of North-American and Australian cities are characterized by the development of low-density neighbourhoods with a low diversity and a car-oriented design (e.g., Brueckner, 2000; Dittmar et al., 2004; Glaeser \& Kahn, 2004; Newman \& Kenworthy, 1996). In order to restrict further urban sprawl and decrease car use, some of these cities (e.g., Perth (Australia) and Calgary (Canada)) have opted for the development of new public transportation services. It is important, however, that low-density developments around these new public transportation lines are transformed in mixeduse and dense neighbourhoods, otherwise a risk exists of creating TAD's instead of TOD's (Curtis, 2008; Curtis \& Olaru, 2010; Olaru et al., 2011; Renne, 2009). 
In some cases, a combination of types occurs. Hong Kong (China), for example, having a successful railway system operating in and around the city centre (i.e., high-density TOD)), expanded their railway system outside the main urban area in order to guide the development of new towns (i.e., New TOD)) (Loo, 2009).

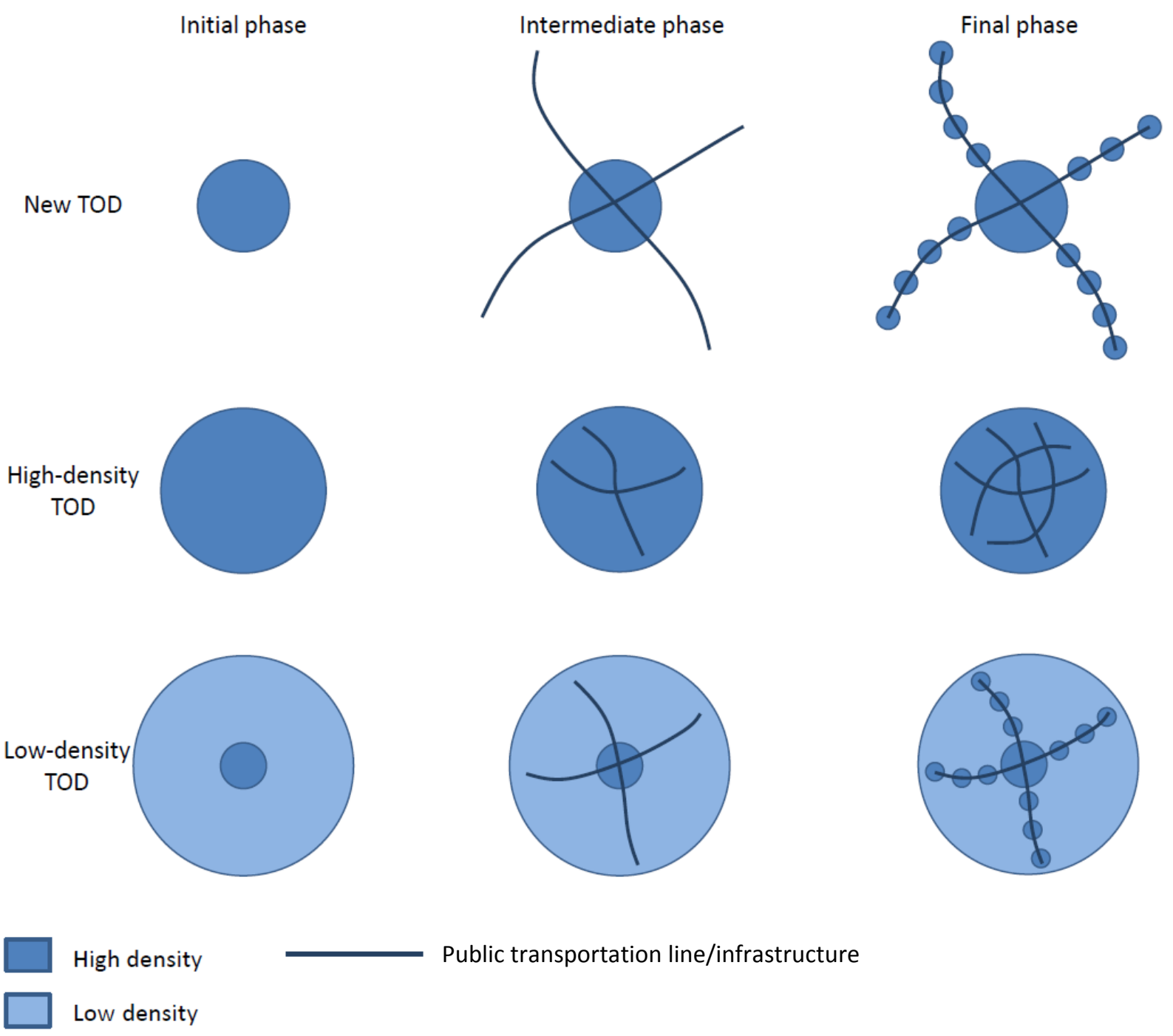

Figure 1: Three types of TOD 


\section{Introducing attitudes in TOD research}

The development of TOD's can result in a dissonance between the actual and preferred residential neighbourhood, albeit in different levels according to the different types of TOD. For the first type (New TOD), there is only a limited change of residential dissonance, since most persons are new residents who have chosen to live in these compact and mixed-use developments. However, a dissonance between the actual and preferred neighbourhood (based on travel-related attitudes) can still occur due to earlier discussed aspects such as distance to work and income levels. In the second type of TOD (High-density TOD), it might become more difficult for initial residents with a preference for car use (dissonant urbanites) to travel by private vehicle due to interventions stimulating car alternatives. Hereby, these urbanites might decide to move to more suburban neighbourhoods and new residents (with positive attitudes toward public transportation, walking and cycling) might be attracted by the developments oriented toward car alternatives. Kamruzzamen et al. (2013b), measuring residential mobility within the city of Brisbane (Australia), has shown that in a two-year period $10.3 \%$ of urban dissonants have moved to another neighbourhood of which $62 \%$ to a non-urban area. Surprisingly, only $25.5 \%$ of suburban dissonants moving relocated to an urban neighbourhood, possibly due to high urban dwelling prices. Policy development should therefore focus on facilitating easy movement for suburban dissonants to urban neighbourhoods. It might also be possible that dissonant urbanites adapt to the built environment and change both their attitudes toward travel and their actual travel behaviour. According to Kamruzzaman et al. (2013a) a decrease in the level of dissonance in TOD areas increases mode shifting behaviour to public transportation and active travel; however travel-related attitudes only seem to change slowly over time. The third type of TOD (Low-density TOD) will, most probably, be facing the highest amount of residential 
dissonance since low-density areas will be converted into compact, mixed-use developments. Car-loving people who self-selected themselves into these neighbourhoods when it was still a car-oriented environment might not be interested in using public transportation made possible by implementing TOD's and still hang on to car use. However, the new built environment will impose restriction on car use, making it more difficult for them to realise their preferred travel behaviour. This dissonance will only reduce gradually when the former residents adapt their attitudes to the new situation and make use of the available car alternatives or when they decide to relocate to other neighbourhoods and when new residents, with a positive stance toward active travel and public transportation, will be attracted to the new built environment (De Vos et al., 2012). It might therefore take a relatively long time for low-density TOD's (in comparison with other TOD types) to become successful.

\section{Future research}

Based on the previous literature review, it could be useful to measure travel-related attitudes and travel behaviour of initial and new residents before and after the implementation of TOD's. Measuring the attitudes of initial residents (especially of lowdensity TOD's) combined with recently developed tools to measure the potential of areas to develop as TOD's (based, among others, on density and diversity indicators (Kamruzzaman et al., 2014; Singh et al., 2014)) could be useful for choosing the route of the new public transportation line in which vicinity compact developments will be created. Choosing an area with a high potential to develop as TOD, based on land use characteristics, and a high amount of residents with a preference for car alternatives could be beneficial for the success rates of TOD's (e.g., public transportation ridership). It might also be interesting to measure 
how the initial residents of a low-density TOD with an affinity toward car use change their travel-related attitudes and their travel behaviour after the new developments. Can a new built environment (with a high density and diversity) change peoples' attitudes toward travel modes and/or change their actual travel behaviour, or will they hang on to car use or even relocate to other low-density suburbs? Although first steps in this direction have been made by Kamruzzaman et al. (2013a, 2013b), longitudinal studies could give new insights in how the built environment can change attitudes and travel behaviour of people. ${ }^{3}$ It might also be useful to analyse attitudes and travel behaviour of new residents in order to look if they were attracted by the new compact developments and possibilities of using car alternatives. According to Lund (2006), access to public transportation is one of the three most important reasons (together with the type and cost of housing) to reside in a TOD. If they choose these neighbourhoods for other purposes however, such as distance to work, residential dissonance could occur, resulting in a higher car use than desired.

\section{References}

Bertolini, L. 1999. Spatial development patterns and public transport: the application of an analytical model in the Netherlands, Planning, Practice and Research 14 (2): 199-210.

Bhat, C. R., Guo, J. Y. 2007. A comprehensive analysis of built environment characteristics on household residential choice and auto ownership levels, Transportation Research B 41: 506526.

Brueckner, J.K. 2000. Urban sprawl: diagnosis and remedies. International Regional Science Review 23 (2), 160-171.

\footnotetext{
${ }^{3}$ It has to be borne in mind that longitudinal studies with panel data are rarely available in travel behaviour research compared to cross-sectional studies.
} 
Calthorpe, P. 1993. The next American metropolis: ecology, community, and the American dream. Princeton, Princeton Architectural Press.

Cao, X., Mokhtarian, P.L., Handy, S.L. 2007. Do changes in neighborhood characteristics lead to changes in travel behavior? A structural equations modeling approach, Transportation 34: 535-556.

Cao, X., Mokhtarian, P. L., Handy, S. L. 2009. Examining the impacts of residential selfselection on travel behaviour: A focus on empirical findings, Transport Reviews 29(3): 359395.

Cervero, R. 1996. Traditional neighborhoods and commuting in the San Francisco Bay Area, Transportation 23(4): 373-394.

Cervero, R. 2007. Transit-oriented development's ridership bonus: a product of self-selection and public policies, Environment and Planning A 39(9): 2068-2085.

Cervero, R., Kang, C.D. 2011. Bus rapid transit impacts on land uses and land values in Seoul, Korea, Transport Policy 18(1): 102-116.

Cervero, R. 1998. The Transit Metropolis: A Global Inquiry. Washington, D.C.: Island Press.

Cervero, R. 2004. Transit-Oriented Development in the United States: Experiences, Challenges and prospects. Washington, D.C.: Transportation Research Board.

CTOD (Center for Transit-Oriented Development) 2010. Performance-based transit-oriented development typology guidebook. Accessible at: http://www.ctod.org. 
Curtis, C. 2008. Evolution of the Transit-oriented Development Model for Low-density Cities:

A Case Study of Perth's New Railway Corridor, Planning, Practice and Research 23(3): 285302.

Curtis, C., Olaru, D. 2010. The relevance of traditional town planning concepts for travel minimization, Planning, Practice \& Research 25(1): 49-75.

Curtis, C., Renne, J.L., Bertolini, L. 2009. Transit Oriented Development: making it happen. Farnham, UK and Burlington, Vermont: Ashgate Publishing.

De Vos, J., Derudder, B., Van Acker, V., Witlox, F. 2012. Reducing car use: changing attitudes or relocating? The influence of residential dissonance on travel behavior, Journal of Transport Geography 22: 1-9.

De Vos, J., Witlox, F. 2013. Transportation policy as spatial planning tool; reducing urban sprawl by increasing travel costs and clustering infrastructure and public transportation, Journal of Transport Geography 33: 117-125.

Dittmar, H., Belzer, D., Autler, A. 2004. An introduction to transit-oriented development. In: Dittmar, H., Ohland, G. (Eds.) The New Transit Town; Best Practices in Transit-Oriented Development. Washington D.C.: Island Press.

Ewing, R., Cervero, R. 2010. Travel and the built environment. A meta-analysis, Journal of the American Planning Association 76(3): 265-294.

Glaeser, E., Kahn, M. 2004. Sprawl and Urban Growth. In: Henderson, J.V., Thisse, J.F. (Eds.) Handbook of Urban and Regional Economics, Vol. 4. Oxford: Oxford University Press. 
Guo, J.Y., Chen, C. 2007. The built environment and travel behavior: making the connection, Transportation 34(5): 529-533.

Handy, S.L., Cao, X., Mokhtarian, P.L. 2005. Correlation or causality between the built environment and travel behavior? Evidence from Northern California, Transportation Research D 10(6): 427-444.

Kamruzzaman, M., Baker, D., Washington, S., Turrell, G. 2013a. Residential dissonance and mode choice, Journal of Transport Geography 33: 12-28.

Kamruzzaman, M., Washington, S., Baker, D., Turrell, G., 2013b. Does residential dissonance impact residential mobility? Transportation Research Record, 2344: 59-67.

Kamruzzaman M., Baker, D., Washington, S., Turrell, G. 2014. Advance transit oriented development typology: case study in Brisbane, Australia, Journal of Transport Geography 34: 54-70.

Knowles, R.D. 2012. Transit Oriented Development in Copenhagen, Denmark: from the Finger Plan to Ørestad, Journal of Transport Geography 22: 251-261.

Loo, B.P.Y. 2009. How would people respond to a new railway extension? The value of questionnaire surveys, Habitat International 33(1): 1-9.

Loo, B.P.Y., Chen, C., Chan, E.T.H. 2010. Rail-based transit-oriented development: lessons from New York City and Hong Kong, Landscape and Urban Planning 97: 202-212.

Lund, H. 2006. Reasons for Living in a Transit-Oriented Development, and Associated Transit Use, Journal of the American Planning Association 72 (3): 357-66. 
Mokhtarian, P.L., Cao, X. 2008. Examining the impacts of residential self-selection on travel behavior: A focus on methodologies, Transportation Research B 43(3): 204-228.

Mu, R., de Jong, M. 2012. Establishing the conditions for effective transit-oriented development in China: the case of Dalian, Journal of Transport Geography 24: 234-249.

Newman, P., Kenworthy, J.R. 1996. The land use-transport connection: An overview, Land Use Policy 13(1): 1-22.

Olaru, D., Smith, B., Taplin, J.H.E. 2011. Residential location and transit-oriented development in a new rail corridor, Transportation Research Part A 45(3): 219-237.

Renne, J.L. 2009. From transit-adjacent to transit-oriented development, Local Environment 14(1): 1-15.

Schlossberg, M., Brown, N. 2004. Comparing transit-oriented development sites by walkability indicators, Transportation Research Record 1887: 34-42.

Schwanen, T., Mokhtarian, P.L. 2004. The extent and determinants of dissonance between actual and preferred residential neighborhood type, Environment and Planning B 31(5): 759784.

Schwanen, T., Mokhtarian, P.L. 2005. What affects commute mode choice: neighborhood physical structure or preferences toward neighborhoods? Journal of Transport Geography 13(1): 83-99.

Singh, Y.J., Fard, P., Zuidgeest, M., Brussel, M., van Maarseveen, M. 2014. Measuring transit oriented development: a spatial multi criteria assessment approach for the City Region Arnhem and Nijmegen, Journal of Transport Geography 35: 130-143. 
Smith, H., Raemaekers, J. 1998. Land use pattern and transport in Curitiba, Land Use Policy 15(3): 233-251.

Stojanovski, T., Lundström, M. J., Haas, T. 2012. Light railways and busways as key driver for sustainable urban development: The Swedish experiences with transit-oriented development (TOD), Paper presented at Annual Transport Conference at Aalborg University.

Sung, H., Oh, J-T. 2011. Transit-oriented development in a high-density city: Identifying its association with transit ridership in Seoul, Korea, Cities 28(1): 70-82.

van Wee, B. 2009. Self-selection: a key to a better understanding of location choices, travel behaviour and transport externalities? Transport Reviews 29: 279-292.

Zemp., S., Stauffacher, M., Lang, D.J., Scholz, R.W. 2011. Classifying railway stations for strategic transport and land use planning: context matters! Journal of Transport Geography 19: 670-679. 